\title{
Identification of Out-of-Plane Material Characteristics through Sheet-Metal Blanking
}

\author{
Špela Bolka ${ }^{1}$ - Janko Slavič ${ }^{2}$ - Miha Boltežar2,* \\ ${ }^{1}$ Hidria Rotomatika, Spodnja Idrija, Slovenia \\ 2 University of Ljubljana, Faculty of Mechanical Engineering, Slovenia
}

The mechanical characteristics of sheet metals are typically identified in the in-plane direction, although the sheet-metal forming processes (e.g., blanking, deep-drawing) are normally applied in the out-of-plane direction. As the mechanical characteristics are not necessarily constant, their direct experimental evaluation through the forming process would enable material monitoring and process optimization, and, additionally, material characterization in the out-of-plane direction. Full, partial (to a certain depth) and sequential (consecutive partial steps to full penetration) blanking experiments are performed on a laboratory blanking apparatus to correlate the out-of-plane material characteristics with the in-plane ones. The well-established in-plane approach to damage is introduced for the out-of-plane direction to determine the isotropic Lemaitre damage variable. Furthermore, yield and ultimate shear stresses are determined and correlated to their respective in-plane counterparts, offering a new insight in the sheet-metal blanking process.

Keywords: cutting and forming, constitutive behavior, elastic-plastic material, mechanical testing, ductile damage, out-of-plane experiment
Highlights
- Experimental out-of-plane sheet-metal material characterization.
- Use of in-plane approach for out-of-plane characterization.
- $\quad$ Direct material characterization and correlation to in-plane parameters.
- Experimental Lemaitre damage characterization in the out-of-plane direction.
- Full, partial and sequential blanking experiments on laboratory blanking apparatus.

\section{O INTRODUCTION}

In sheet-metal forming, for instance blanking, shearing or deep drawing, identification of material mechanical properties (e.g. yield stress, ultimate stress, fracture point or material anisotropy) is crucial for manufacturing of high quality parts. The material parameters are typically determined experimentally, through in-plane tensile or shear tests, which require special preparation of specimens and cannot be applied continuously. As material characteristics may vary, a direct characterization process would enable fast correlation of current material characteristics to those of the standardized in-plane experiments and, thus, opened possibilities for process optimization.

The identification of yield and ultimate stresses in the in-plane direction is well documented and standardized. On the other hand, the evaluation of fracture point in ductile metals can be approached through several mechanisms [1] and [2], leading to different experimental evaluation procedures. Among the mechanisms, roughly grouped into micromechanical models (e.g. [3] to [6]), uncoupled models (e.g. [1] and [2]) and coupled phenomenological models (e. g. [1], [7] and [8]), the Lemaitre coupled phenomenological model, following the continuum damage mechanics (CDM) may be considered as most appropriate for direct and continuous material characterization. The model considers material damage through degradation of macroscopic material properties, for instance Young's modulus of elasticity or microhardness [9] and [10]. Damage is described as gradual material weakening due to initiation, growth and propagation of microscopic cracks and voids, resulting in macroscopic crack [1] and [11]. The Lemaitre damage model, based on experimental in-plane identification of parameters or on an inverse numerical analysis, has been successfully implemented in both in-plane (e.g. [7] and [12]) and out-of-plane (e.g. [13] and [14]) numerical applications. Nevertheless, extensions of the model have been proposed, for example including damage anisotropy (e.g. [15] and [16]) or Lode angle (e.g. [1] and [17]) for low stress-triaxiality applications.

Experimental identification of Lemaitre damage variable is typically performed through observation of variation in modulus of elasticity [11] and [12] or microhardness [15] and [18] by the uniaxial tensile experiment. The out-of-plane damage value is then estimated through the in-plane measurements [10].

In the out-of-plane direction, several attempts of experimental characterization have been reported by the use of shear-punch testing, mainly as a validation of a numerical analysis. In most researches, yield 
and ultimate shear stress are identified and correlated to tensile stresses [19] and [20] and Abendroth and Kuna [21] used the shear punching process for inverse identification of the micromechanics-based GTN damage model parameters. But direct identification of the fracture and damage parameters has not yet been fully concluded [20]. Therefore, sheet-metal blanking would offer similar options to the shear-punch testing, resulting in total separation of the sheet metal, and thus enabling fracture point determination. Furthermore, the identification and optimization of the blanking process, although one of the most frequently used industrial processes for sheet laminations, is mostly focused on the optimization of the tools [22] to [24] or electromagnetic properties of the finished part [25]. Therefore would a direct material characterization procedure enable further understanding and optimization of the process.

In this research, sheet-metal blanking process was used to identify the out-of-plane material characteristics. Full, partial (to a certain depth) and sequential (consecutive partial steps up to full penetration) quasi-static and dynamic blanking experiments were performed in order to obtain the yield and ultimate stress and the material-damage progression directly from an out-of-plane experiment. A novel blanking apparatus (presented in detail in [26]) offers an out-of-plane experimental analysis of the sheet metal. The identified material parameters were compared to the material parameters obtained from classic uniaxial tensile tests.

The article is organized as follows. In Section 1 the theoretical background of the Lemaitre damage model and the small-strain plasticity are presented. Section 2 details the experimental approach. The experimental results are presented and discussed in Section 3. The conclusions are drawn in Section 4.

\section{THEORETICAL BACKGROUND}

In sheet-metal blanking process, a non-linear material response is accompanied with different phenomena of material degradation. The Lemaitre phenomenological damage model has an advantage of observing the degradation from an averaged, macroscopic point of view, therefore characterization of different damage phenomena is not required.

In this section, the constitutive equations of plasticity and the original formulation of the Lemaitre damage model are briefly summarized. The small-strain rate-independent plasticity with isotropic material hardening and isotropic damage is considered.
The Lemaitre damage model defines the isotropic scalar damage variable $D(0 \leq D \leq 1)$ as the ratio of the damaged area $S$ and the virginal (undamaged) area $S_{0}$ at any given plane in the volume of the material [27]:

$$
D=1-\frac{S}{S_{0}}
$$

Using the hypothesis of strain equivalence [28], the stress tensor $\sigma$ of the undamaged material is replaced by the effective stress tensor $\tilde{\sigma}$ in the damaged material:

$$
\tilde{\sigma}=\frac{\sigma}{1-D} .
$$

In the framework of small-strain rate-independent plasticity, the total strain after the yield can be decomposed into the elastic $\boldsymbol{\varepsilon}^{\mathrm{e}}$ and plastic $\boldsymbol{\varepsilon}^{\mathrm{p}}$ (see [29] for details):

$$
\varepsilon=\varepsilon^{e}+\varepsilon^{p} .
$$

The Helmholtz free energy $\psi$ is defined as the free potential, depending on the internal variables, i.e., the elastic strain $\boldsymbol{\varepsilon}^{\mathrm{e}}$, the internal variables associated with isotropic hardening $\kappa$ and the isotropic damage variable $D$. The free energy can be decomposed into the elastic-damage $\psi^{\text {ed }}$ and the plastic $\psi^{\mathrm{p}}$ free energy [28]:

$$
\begin{aligned}
& \psi\left(\varepsilon^{\mathrm{e}}, \kappa, D\right)=\psi^{\text {ed }}\left(\varepsilon^{e}, D\right)+\psi^{\mathrm{p}}= \\
= & {\left[\frac{1}{2} \varepsilon^{\mathrm{e}}:(1-D) \mathbf{D}: \varepsilon^{\mathrm{e}}\right]+\left[\bar{\rho} \psi^{\mathrm{I}}(\kappa)\right], }
\end{aligned}
$$

where $\bar{\rho}$ represents the material density and $\psi^{\mathrm{I}}(\kappa)$ is the free energy associated with isotropic hardening. D is the standard elasticity tensor. The thermodynamic forces associated with the internal variables (see [29]) are determined as:

$$
\begin{gathered}
\boldsymbol{\sigma}=\bar{\rho} \frac{\partial \psi^{\mathrm{ed}}\left(\varepsilon^{\mathrm{e}}, D\right)}{\partial \boldsymbol{\varepsilon}^{\mathrm{e}}}=(1-D) \mathbf{D}: \varepsilon^{\mathrm{e}}, \\
R=\bar{\rho} \frac{\partial \psi^{\mathrm{p}}(\kappa)}{\partial \kappa}=R(\kappa), \\
Y=\bar{\rho} \frac{\partial \psi^{\mathrm{ed}}\left(\varepsilon^{\mathrm{e}}, D\right)}{\partial D}=-\frac{1}{2} \varepsilon^{\mathrm{e}}: \mathbf{D}: \varepsilon^{\mathrm{e}},
\end{gathered}
$$

where $\sigma$ is the stress tensor, $R$ is the thermodynamic force associated with isotropic hardening and $Y$ is the thermodynamic force associated with damage. 
For the Lemaitre damage model, the thermodynamic damage force, or the energy density release rate, is determined as [26]:

$$
-Y=\frac{\sigma_{\mathrm{eq}}^{2}}{2 E(1-D)^{2}} \cdot\left[\frac{2}{3}(1+v)+3(1-2 v)\left(\frac{p}{\sigma_{\mathrm{eq}}}\right)^{2}\right],
$$

where:

$$
\sigma_{\text {eq }}=\sqrt{\frac{3}{2}}\|\mathbf{s}\|,
$$

is the von Mises equivalent stress with $\mathbf{s}$ as the stress deviator tensor. $p=\frac{1}{3} \operatorname{tr}(\sigma)$ represents the hydrostatic stress, $E$ is the Young's modulus of elasticity and $v$ is the Poisson's ratio.

The evolution of the internal variables is derived by assuming the existence of a scalar potential of the dissipation $\Psi$ that can be decomposed into the plastic $\Psi^{\mathrm{p}}$ and damage $\Psi^{\mathrm{d}}$ components (see [10] for details):

$$
\Psi=\Psi^{\mathrm{p}}+\Psi^{\mathrm{d}}=\Phi+\frac{r}{(1-D)(s+1)}\left(\frac{-Y}{r}\right)^{s+1},
$$

where $\Phi$ is the yield function and $r$ and $s$ are the material parameters of the damage model. For the von Mises yielding, the yield function is given as:

$$
\Phi\left(\sigma, \varepsilon_{\mathrm{eq}}^{\mathrm{p}}, D\right)=\frac{\sigma_{\mathrm{eq}}}{1-D}-\sigma_{\mathrm{y}},
$$

where $\sigma_{\mathrm{y}}$ represents the current yield stress:

$$
\sigma_{\mathrm{y}}=\sigma_{\mathrm{y} 0}+R(\kappa)
$$

with $\sigma_{\mathrm{y} 0}$ as the initial yield stress and $R(\kappa)$ is the isotropic hardening function, with the hardening variable $\kappa$ equal to the accumulated plastic strain $\bar{\varepsilon}^{\mathrm{p}}$ (see [27] for details):

$$
\bar{\varepsilon}^{\mathrm{p}}=\sqrt{\frac{2}{3}\left\|\varepsilon^{\mathrm{p}}\right\|}
$$

The evolution of the internal variables is determined by:

$$
\begin{gathered}
\dot{\boldsymbol{\varepsilon}}^{\mathrm{p}}=\dot{\gamma} \frac{\partial \Psi}{\partial \boldsymbol{\sigma}}=\dot{\gamma} \mathbf{N}, \\
\dot{\kappa}=-\dot{\gamma} \frac{\partial \Psi}{\partial R}=\dot{\gamma}=\dot{\boldsymbol{\varepsilon}}^{\mathrm{p}}, \\
\dot{D}=\dot{\gamma} \frac{\partial \Psi}{\partial Y}=\dot{\gamma} \frac{1}{1-D}\left(\frac{-Y}{r}\right)^{s},
\end{gathered}
$$

where $\dot{\gamma}$ represents the plastic multiplier and $\mathbf{N}$ is the plastic flow vector. Assuming an associative plastic flow it follows:

$$
\mathbf{N}=\sqrt{\frac{3}{2}} \frac{\mathbf{s}}{\|\mathbf{s}\|}
$$

The evolution of the internal variables is subjected to the Kuhn-Tucker loading/unloading conditions:

$$
\dot{\gamma} \geq 0, \quad \Phi \leq 0, \quad \dot{\gamma} \cdot \Phi=0 .
$$

\section{EXPERIMENTAL PROCEDURE}

Two sets of experiments were performed - the classic uniaxial tensile experiments and the blanking experiments.

\subsection{Material}

A low-alloyed steel sheet metal M400-50A HP of nominal thickness $0.5 \mathrm{~mm}$ was used for all the experiments in this investigation. All the specimens were obtained from the same part of the sheet-metal roll. The mechanical characteristics will be presented later on, as obtained from uniaxial tensile experiments. The uniaxial tensile test were performed in the steelsheet rolling direction.

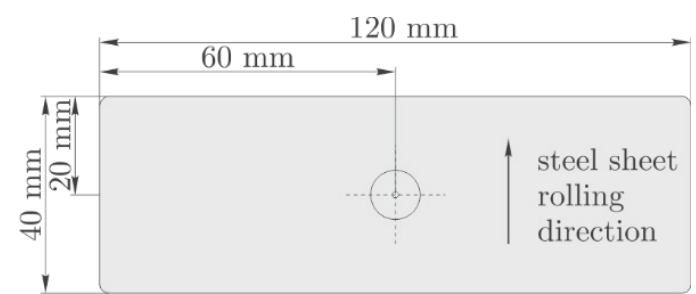

Fig. 1. Specimen used for blanking experiments with the indicated circular blanking shape

Standard specimens (ISO 6892-1) for the tensile testing were obtained by blanking. The edges of the samples were additionally smoothed to reduce the edge effects in the tensile tests. For the blanking experiments, specimens, an example is shown in Fig. 1 , were obtained by water-jet cutting. The central hole with a diameter of $1.2 \mathrm{~mm}$, used for the punchdisplacement measurement (explained later), was obtained by drilling. 


\subsection{In-Plane Experimental Setup (Tensile Experiments)}

Full and stepwise uniaxial tensile experiments were performed using an Instron universal hydraulic machine. Full tensile tests were performed according to the ISO 6892-1 standard. Stepwise uniaxial tensile tests were based on the same standardized procedure. For every $2 \%$ of deformation the sample was unloaded and loaded again up to full rupture.

Strain, elongation, force and stress were measured at the hydraulic head with the built-in sensors.

\subsection{Out-of-Plane Experimental Setup (Blanking Experiments)}

Blanking experiments were performed using the custom-built laboratory blanking apparatus [24]. The apparatus enables quasi-static (blanking speeds of about $0.1 \mathrm{~mm} / \mathrm{s}$ ) and dynamic blanking experiments (blanking speeds depending on the thickness of the sheet metal and the circumference of the cutting tools; typically about $200 \mathrm{~mm} / \mathrm{s}$ or more).

The quasi-static blanking is performed by turning a fine-threaded screw in the fixation block (Fig. 2) that propels the piston and the punch forward in the cutting module, shown in Fig 4. For dynamic blanking, the blanking apparatus is elevated at one end for an angle $\alpha$ (Fig. 3) and the impactor is released from rest from an arbitrary position on the slope. Typically, the blanking apparatus is raised for about $5^{\circ}$. The initial potential energy of the impactor is transformed to the initial kinetic energy of the piston and the punch at the base of the slope. The position of the impactor on the slope can be determined up to $1 \mathrm{~mm}$ accurately, resulting in $\pm 5 \mathrm{~mm} / \mathrm{s}$ control of the blanking speed.

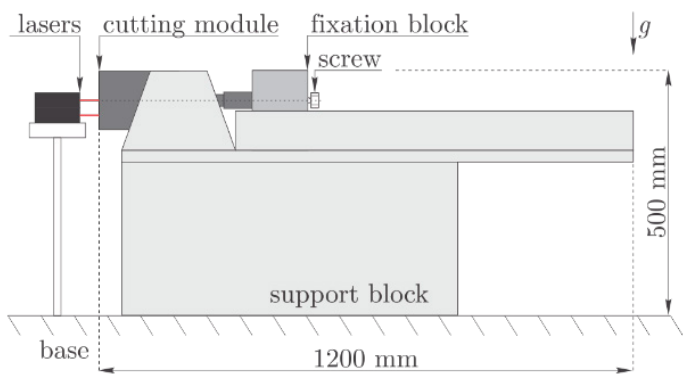

Fig. 2. Custom blanking apparatus in configuration for quasi-static experiments; $g$ represents acceleration due to gravity

The blanking is performed in the cutting module (Figs. 4 and 5). The sheet metal is held in place by 8 strong magnets that are inserted into the die. The punch displacement is measured on the punch tip, a 1-mm- diameter extension from the tip, using a Keyence LG82 displacement laser. The punch force is measured by a Kistler 9061A ring-type force transducer, mounted behind the punch. The punch acceleration is measured using a Brül\&Kjær, type 8309 accelerometer.

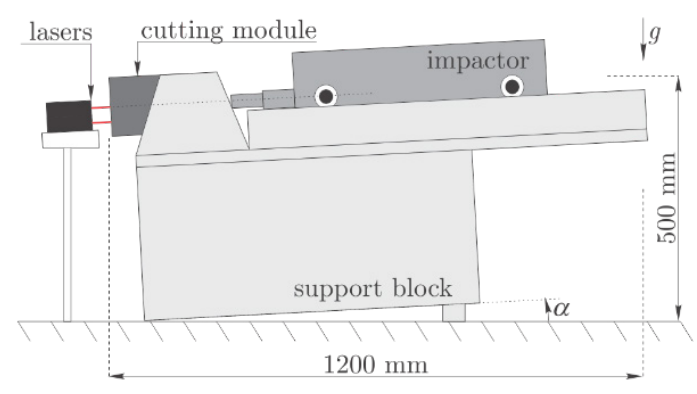

Fig. 3. Custom blanking apparatus: configuration for dynamic experiments; $g$ represents acceleration due to gravity

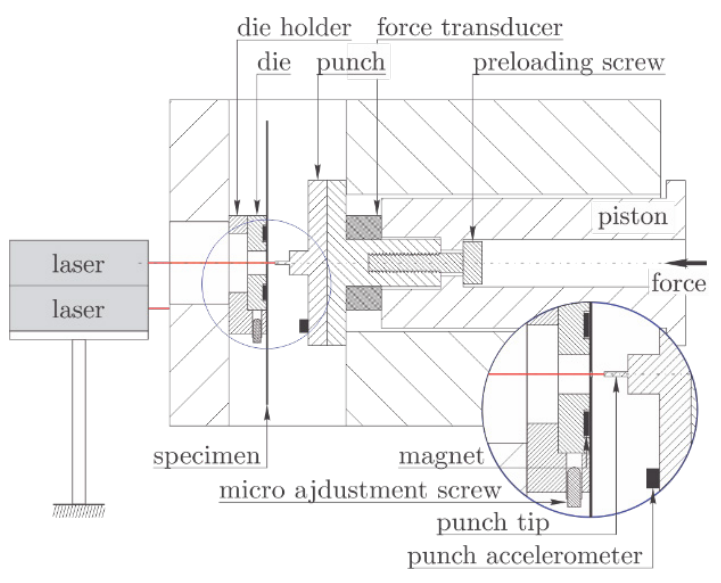

Fig. 4. The cutting module

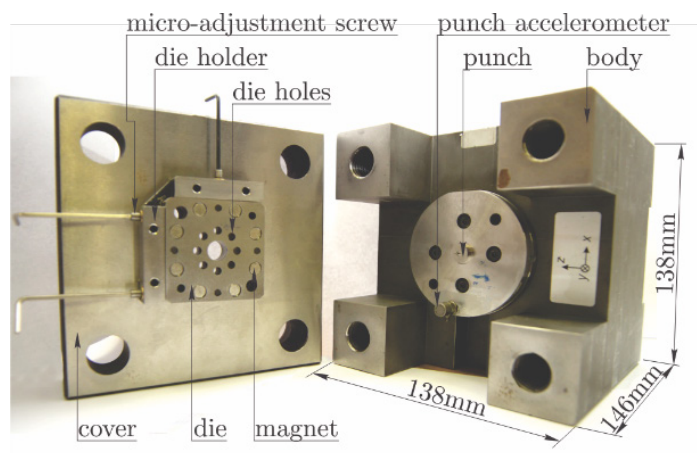

Fig. 5. The cutting module in an opened position

For this research, a centric circular punch-die set with a nominal diameter of $10 \mathrm{~mm}$ and a clearance of $25 \mu \mathrm{m}$ per radius was used. The set was not lubricated and all the experiments were performed at room temperature (about $23^{\circ} \mathrm{C}$ ). The full experiments were 
performed quasi-statically with a blanking speed of about $0.1 \mathrm{~mm} / \mathrm{s}$ and dynamically with blanking speeds of approximately $(200,250,300,350) \mathrm{mm} / \mathrm{s}$. The partial and sequential quasi-static experiments were performed with a blanking speed of about $0.1 \mathrm{~mm} / \mathrm{s}$, whereas the dynamic blanking experiments were performed with a blanking speed just high enough for the punch to reach the designated depth.

The partial experiments were performed up to depths of $(100,200,300,350) \mu \mathrm{m}$ and the sequential experiments were performed in steps of $50 \mu \mathrm{m}$. The repeatability of the laboratory blanking apparatus is above $95 \%$ and is discussed in detail in [24].

In all the out-of-plane experiments, at least five trials (to obtain minimal statistical requirements) were performed and averaged. Data was smoothed using a Hann window over 11 measurement points.

\section{RESULTS}

\subsection{In-Plane Experimental Results}

\subsubsection{Yield Stress and Material Hardening Law}

The material hardening data was obtained from standard uniaxial tensile tests (results shown in Fig. 5). As the material exhibits a Lüder plateau, a combined isotropic hardening material model was defined. After the initial yield stress $\sigma_{\mathrm{y} 0}$ the material exhibits a linear hardening behavior with a hardening coefficient $K$ :

$$
\sigma_{\mathrm{y}}=\sigma_{\mathrm{y} 0}+K \bar{\varepsilon}^{\mathrm{p}},
$$

where $\bar{\varepsilon}^{\mathrm{p}}$ is the accumulated plastic strain. After the limit accumulated plastic strain $\bar{\varepsilon}^{\mathrm{p} 0}$ is reached, the material exhibits an exponential Voce/saturation-type hardening law [28]:

$$
\sigma_{\mathrm{y}}=\sigma_{\mathrm{y} 1}+\left(\sigma_{\infty}-\sigma_{\mathrm{y} 1}\right)\left(1-e^{-\bar{\varepsilon}^{\mathrm{p}} m}\right),
$$

where $\sigma_{\mathrm{y} 1}=\sigma_{\mathrm{y} 0}+K \bar{\varepsilon}^{\mathrm{p} 0}, \sigma_{\infty}$ is the saturation stress. The parameters of the combined material model for the rolling direction of steel are given in Table 1. The fitting of the combined model to the experimental data is shown in Fig. 5.

\subsubsection{Damage Parameters}

As shown in [12], it follows from Eqs. (1), (2) and (5a):

$$
D=1-\frac{E}{E_{0}}
$$

where $E$ and $E_{0}$ are the current and initial Young's modulus of elasticity.

Under the assumption of $s=1$, the damage parameter $r$ was obtained from the sequential tensile tests [12]. For the uniaxial tensile test, Eq. (6) is simplified to:

$$
-Y=\frac{\sigma^{2}}{2 E(1-D)^{2}} .
$$

Using Eq. (18) in Eq. (12c), damage propagation in relation to the accumulated plastic deformation can be written as:

$$
\frac{\mathrm{d} D}{\mathrm{~d} \bar{\varepsilon}^{\mathrm{p}}}=\frac{\sigma^{2}}{2 \operatorname{Er}(1-D)^{2}} .
$$

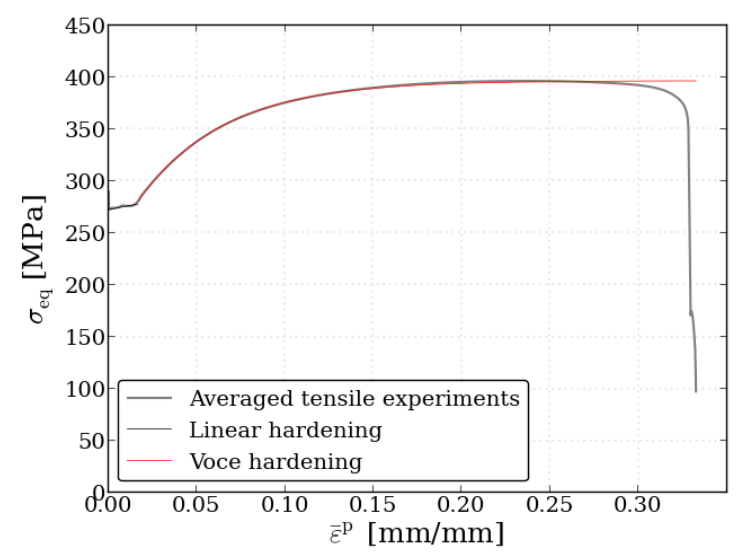

Fig. 6. Averaged full uniaxial tensile experiments with modelled hardening curves

It follows that the damage parameter $r$ is equal to:

$$
r=\frac{\sigma^{2}}{2 E(1-D)^{2}} \frac{\mathrm{d} D}{\mathrm{~d} \bar{\varepsilon}^{\mathrm{p}}} .
$$

For statistical reasons as mentioned above, five sequential tests were performed, as shown in Fig. 6. As recommended by [10], the elastic modulus was determined on the unloading part of each step. Fig. 7 shows the degradation of the elastic modulus and the accumulation of damage in relation to the accumulated plastic strain. For each unloading point the minimum and maximum values of the parameters are shown by the error bar. Using Eq. (20), it follows $r=0.953 \mathrm{MPa}$.

\subsection{Out-of-Plane Experimental Results}

Full, partial and sequential experiments were performed quasi-statically and dynamically. The 
mechanics of the blanking experiments is different to the mechanics of the in-plane experiments. In contrast to the clamped specimen in the tensile test, in the blanking experiment the cutting tools and the specimen initially come into contact and the cutting tools affect the material's response in the initial elastic zone. Therefore, the resulting blanking force vs. punch penetration $(P-d)$ diagrams do not show all the distinct characteristics of the total stress vs. total strain diagrams resulting from the tensile experiment. The elastic response of the material was therefore identified during the unloading phase when the cutting tools are retracting from the material.

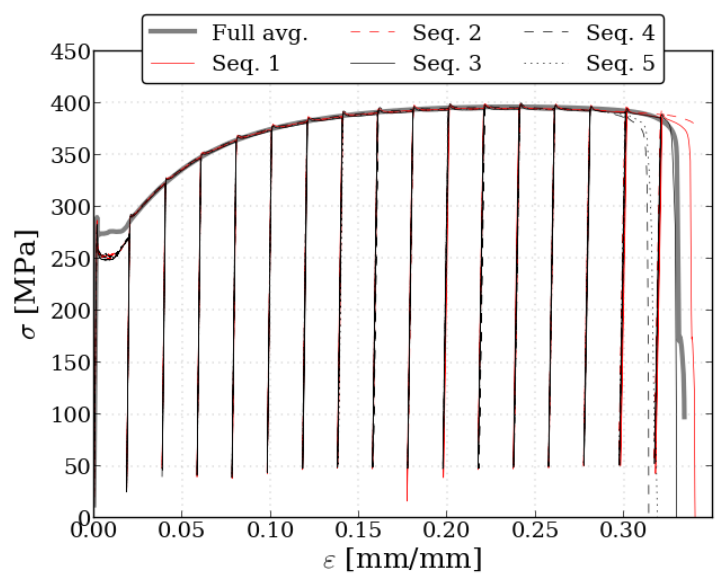

Fig. 7. Sequential uniaxial tensile experiments, compared to averaged full uniaxial tensile experiment

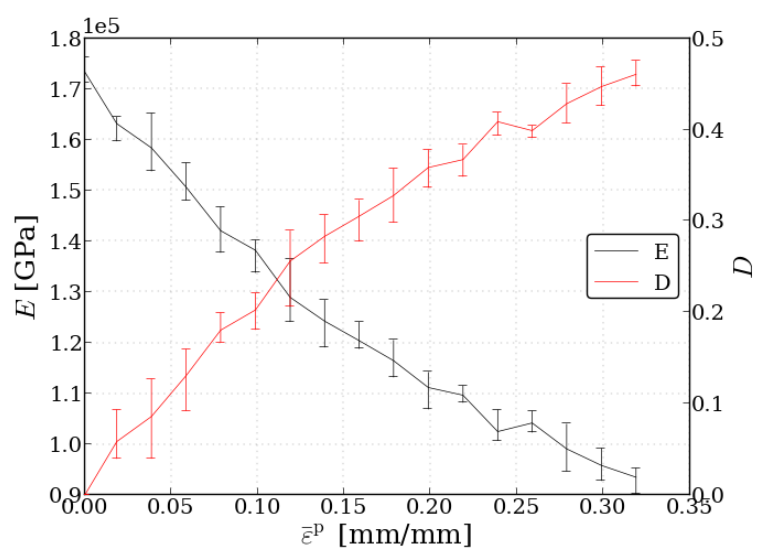

Fig. 8. Identification of damage for uniaxial tensile experiments

Although the inertial forces are accounted for (see [24] for details), complete elimination is not possible at higher blanking speeds, as the dynamics of the process becomes more pronounced (Fig. 8). However, during the unloading part, a similar slope of the $\mathrm{P}-d$ diagram is expected.

\subsubsection{Yield and Ultimate Stress}

The shear stress can be estimated as (see [19]):

$$
\tau=\frac{P}{2 \pi r_{\text {avg }} t},
$$

where $r_{\mathrm{avg}}=\left(r_{\mathrm{die}}+r_{\text {punch }}\right) / 2$ is the average radius of the cutting tools and $t$ is the thickness of the specimen. The correlation between the ultimate and the yield stress in the tensile and shear directions can be obtained from the $P-d$ diagram for the full blanking experiments. Averaged diagrams (at least five measurements for each measurement type) for different blanking speeds are shown in Fig. 8 and the effect of the blanking speed on the shear ultimate $\tau_{\mathrm{u}}$ and the yield $\tau_{\mathrm{y}}$ stress during blanking in comparison to the tensile ultimate $\sigma_{\mathrm{u}}$ and yield $\sigma_{\mathrm{y}}$ stress is shown in Fig. 9. Yielding was determined by the use of partial blanking experiments (discussed later) and a linear approximation. It was determined from partial blanking experiments that the plastic deformation of the specimens occurred at an approximate punch penetration of $30 \mu \mathrm{m}$. A linear approximation was used on the $P-d$ data to acquire the blanking force at the yield.

The quasi-static ultimate shear stress is lower than the ultimate tensile stress (ratio about 1.06), whereas the dynamic ultimate shear stress is slightly higher than the ultimate tensile stress (ratio of approximately 0.99). In contrast, the yield shear stress is lower than the tensile yield stress (1.45), but it increases with the blanking speed (from about 1.30 at a blanking speed of $200 \mathrm{~mm} / \mathrm{s}$, and to 1.15 at a blanking speed of 350 $\mathrm{mm} / \mathrm{s}$ ).

Increase in process speed may lead to thermal softening of the material due to the heat generated inside the sheet-metal. The temperature increase during blanking was discussed in the literature from experimental and numerical point of view (see [24]), but for the material, presented in this study, no significant effects of generated heat were observed at different blanking speeds. Therefore the thermal effects will be disregarded in this study.

Table 1. Material hardening parameters in the rolling direction, obtained from tensile tests

\begin{tabular}{lcccccc}
\hline Parameter & $E_{\text {rolling }}[\mathrm{GPa}]$ & $\sigma_{\mathrm{y} 0}[\mathrm{MPa}]$ & $\varepsilon^{\mathrm{p} 0}[\mathrm{~mm} / \mathrm{mm}]$ & $K[\mathrm{MPa}]$ & $\sigma_{\infty}[\mathrm{MPa}]$ & $m$ \\
\hline Value & 175.6 & 273 & 0.0168 & 321.698 & 396.623 & 20.704 \\
\hline
\end{tabular}




\subsubsection{Damage Identification}

For damage identification, partial (Fig. 10) and sequential (Fig. 11) quasi-static and dynamic blanking experiments were performed. As can be seen from Fig. 10, the partial dynamic experiments conform well with the full dynamic experiments. By lowering the initial kinetic energy of the punch for the stepwise experiments, the stepwise steps show a more quasistatic-like curve, but still follow closely the full experiments (Fig. 11).

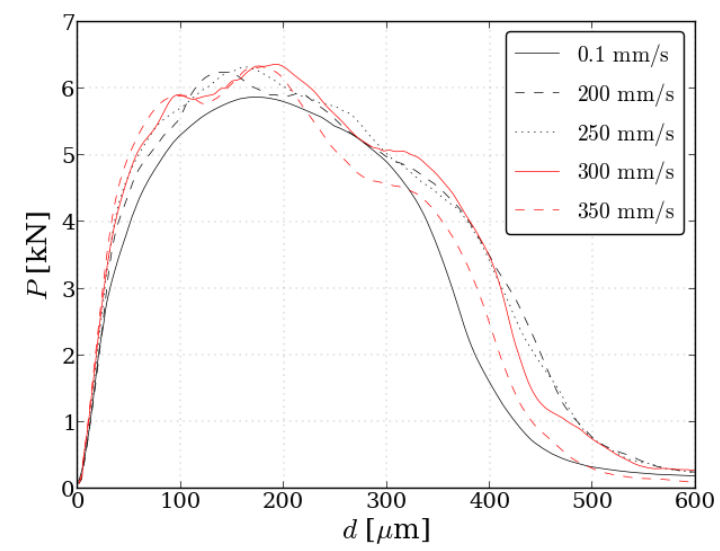

Fig. 9. Averaged blanking diagrams at different blanking speeds

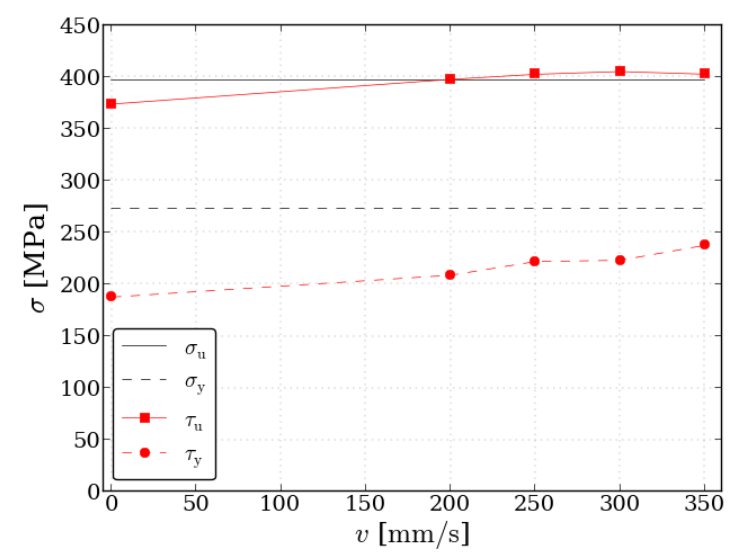

Fig. 10. Correlation of uniaxial tensile and blanking yield and ultimate stresses

The material degradation was determined, similar to the uniaxial tensile tests, by observing the gradient $G=\mathrm{d} P / \mathrm{d} d$ during the unloading phase of the blanking for the sequential steps (Fig. 12). In contrast to the tensile experiments, where the unloading slope of the curve is approximately linear, the blanking partial and sequential unloading curves exhibit non-linearities that are attributed to the contact conditions between the cutting tools and the specimen. Fig. 13 shows the identified unloading gradients for partial and sequential experiments at different punch penetration depths. The gradients for the unloading data increase approximately to the maximum blanking force and then start to decrease rapidly.

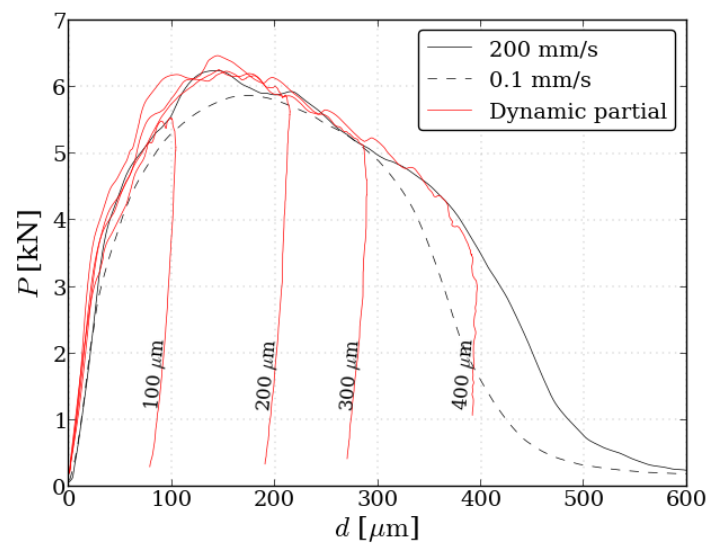

Fig. 11. Averaged partial experiments

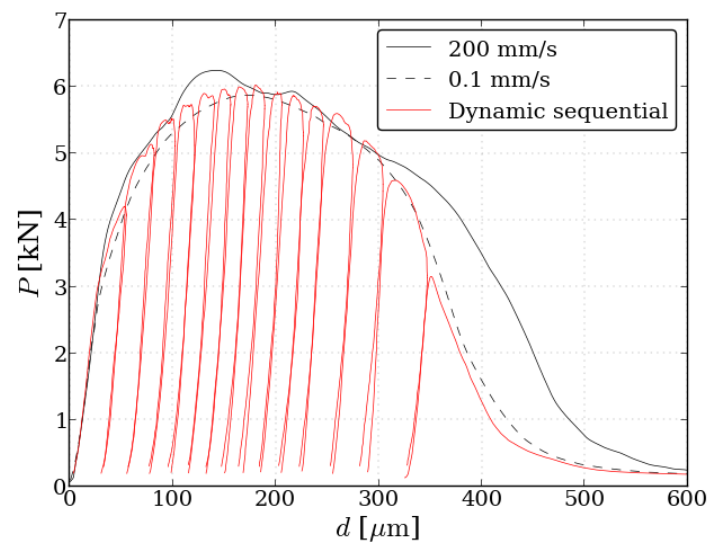

Fig. 12. Averaged sequential dynamic blanking experiments

For an approximately equal punch-penetration depth, similar gradient values are obtained from the quasi-static and the dynamic partial and sequential experiments. Only the small, $50 \mu \mathrm{m}$ steps reveal the peak gradient at the maximum force depth. The $\mathrm{P}-d$ diagram up to the maximum force is usually assumed to show the hardening of the sheet-metal, followed by damage initiation and shearing after the force peak [29]. The shearing zone ends with an abrupt fracture of the sheet metal. By investigating metallographic samples, the fracture point was determined to be at approximately $350 \mu \mathrm{m}$. This can also be seen from the sequential experiments - even for sequential steps with a nominal depth of $50 \mu \mathrm{m}$, the final fracture occurred at a depth of approximately $350 \mu \mathrm{m}$.

A comparison of the damage accumulation during the uniaxial tensile experiment and of the damage-like 
variable during the blanking experiment is shown in Fig 14.

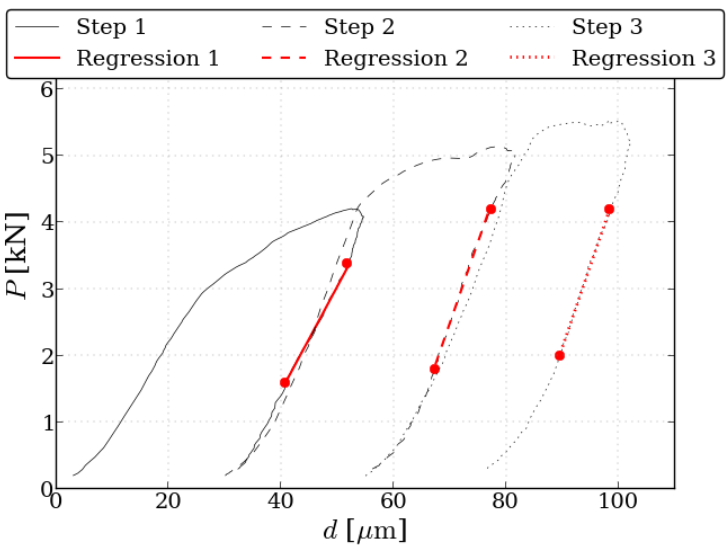

Fig. 13. Identification of damage from sequential blanking experiments

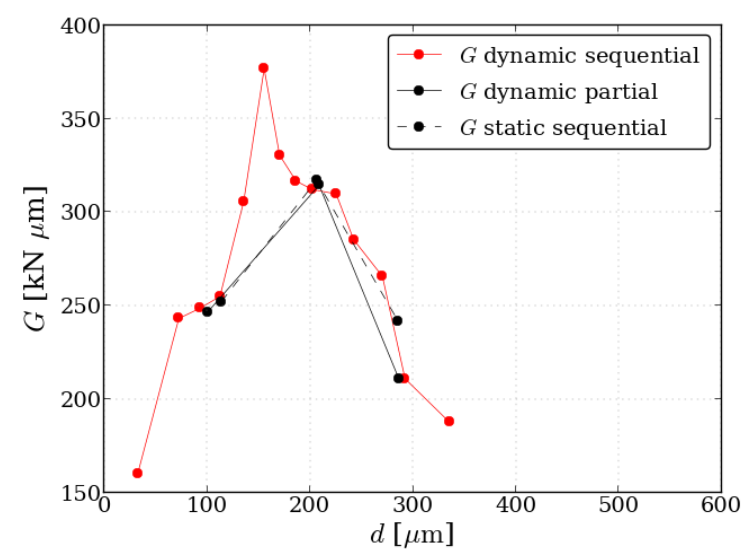

Fig. 14. Damage at different punch penetrations for sequential and partial experiments

As the strains during the blanking cannot be directly characterized, neither as pure tensile nor as pure shear strains [19] and [29], relative plastic displacement is used to compare the values of the damage variable during tensile and blanking experiments instead of the accumulated plastic strain.

The relative plastic displacement for the tensile experiment $d_{\text {rel, }}$ is determined as:

$$
d_{\mathrm{rel}, \mathrm{t}}=\frac{d_{\mathrm{y}, \mathrm{t}}}{d_{\mathrm{f}, \mathrm{t}}}
$$

where $d_{\mathrm{y}, \mathrm{t}}$ is the displacement after the material yield and $d_{\mathrm{f}, \mathrm{t}}$ is the displacement at fracture for the tensile experiment. The relative plastic displacement for the blanking experiment is determined as:

$$
d_{\mathrm{rel}, \mathrm{b}}=\frac{d_{\mathrm{p}, \mathrm{b}}}{t}
$$

where $d_{\mathrm{p}, \mathrm{b}}$ is the displacement after the peak force and $t$ is the sheet-metal thickness. The damage coming from the blanking is characterized as:

$$
D_{\mathrm{b}}=1-\frac{G}{G_{0}},
$$

$G_{0}$ represents the unloading gradient at the highest peak. A further analysis was performed, the same as with the data from the tensile experiments.

In the tensile experiments the Young's modulus was reduced from an initial $177 \mathrm{MPa}$ to a final 94 $\mathrm{MPa}$, or, about $46 \%$. Similarly, in the blanking experiments the gradient was reduced from the steepest $376 \mathrm{kN} / \mathrm{mm}$ to $160 \mathrm{kN} / \mathrm{mm}$, which is about 57 $\%$. This is consistent with the results obtained by [17].

However, the observation of the relative plastic displacement shows that, while during the uniaxial tensile experiment, damage accumulation starts almost immediately with the plastification, the accumulation of damage in the out-of-plane direction starts after the maximum force is reached, resulting in a smaller relative plastic displacement at fracture.

\section{CONCLUSIONS}

In this research, an experimental procedure to directly identify material parameters in the out-of-plane direction is proposed. The in-plane procedures from uniaxial tensile testing are implemented in the outof-plane blanking experiments to determine shear yield and ultimate stresses and material damage accumulation up to fracture point. The out-of-plane values are compared to the values obtained from the uniaxial tensile experiment. Full, partial and sequential blanking experiments at various blanking speeds were performed to obtain the ultimate and the yield stress and the damage accumulation in relation to the punch depth in the out-of-plane direction. The damage was identified from the blanking force vs. punch penetration unloading gradient of the partial and sequential steps.

The damage initiation in the out-of-plane direction can only be observed with sufficiently small sequential steps, as can be seen from the results above. Furthermore, out-of-plane damage dependency on the step size and/or process speed needs to be assessed for the tested material using partial and sequential experiments with different step sizes.

Similarly, the yield and ultimate shear stresses should be tested at different process speeds in order to perform full correlation with the in-plane data. Furthermore, as the yield stress evaluation in the 
out-of-plane direction is influenced by the materialpunch contact conditions, additional care should be taken in order to ensure equal contact conditions (e.g. lubrication, tool wear, etc.), otherwise the parameter might monitor the variation of the contact conditions instead.

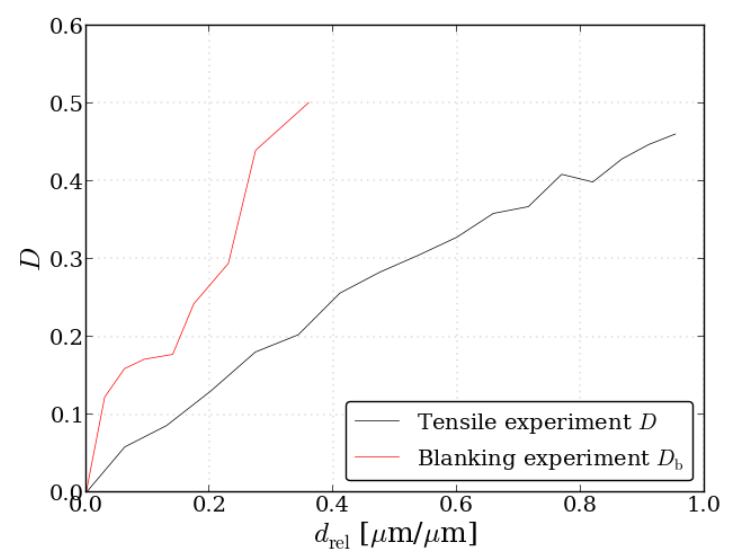

Fig. 15. Correlation of tensile and blanking damage propagation up to fracture

With the integration of the proposed procedure into an industrial blanking press, an on-line monitoring of the material quality could be obtained from which process monitoring and optimization could be achieved, for example by correlating the blanking speed to the material fracture point. Furthermore, with appropriate extensions to the Lemaitre damage model formulation, damage parameters for a fully anisotropic Lemaitre damage model could be determined.

\section{ACKNOWLEDGEMENTS}

This operation was partially financed by the European Union, European Social Fund (Grant nr. MR-10/103).

\section{REFERENCES}

[1] Cao, T.-S., Gachet, J.-M., Montmitonnet, P., Bouchard, P.-0. (2014). A Lode-dependent enhanced Lemaitre model for ductile fracture prediction at low stress triaxiality. Engineering Fracture Mechanics, vols. 124-125, p. 80-96, D0l:10.1016/j. engfracmech.2014.03.021.

[2] Li, H., Fu, M., Lu, J., Yang, H. (2011). Ductile fracture: Experiments and computations. International Journal of Plasticity, vol. 27, no. 2, p. 147-180, D0l:10.1016/j. ijplas.2010.04.001.

[3] Gurson, A.L. (1977). Continuum theory of ductile rupture by void nucleation and growth. Part I: yield criteria and flow rules for porous ductile media. Journal of Engineering Materials and Technology, vol. 99, no. 1, p. 2-15, Dol:10.1115/1.3443401.
[4] Tvergaard, V., Needleman, A. (1984). Analysis of the cup-cone fracture in a round tensile bar. Acta Metallurgica, vol. 32, no. 1, p. 157-169, DOl:10.1016/0001-6160(84)90213-X.

[5] Nahshon, K., Hutchinson, J. (2008). Modification of the Gurson model for shear failure. European Journal of Mechanics - A/Solids, vol. 27, no. 1, p. 1-17, D0l:10.1016/j. euromechsol.2007.08.002.

[6] Starman, B., Vrh, M., Halilovič, M., Štok, B. (2014). Advanced modelling of sheet metal forming considering anisotropy and Young's modulus evolution. Strojniški vestnik - Journal of Mechanical Engineering, vol. 60, no. 2, p. 84-92, DOl:10.5545/sv-jme.2013.1349.

[7] Saanouni, K. (2008). On numerical prediction of ductile fracture in metal forming. Engineering Fracture Mechanics, vol. 75 , no. 11, p. 3545-3559, D0l:10.1016/j. engfracmech.2007.02.023.

[8] Lemaitre, J. (1985). A continuous damage mechanics model for ductile fracture. Journal of Engineering Materials and Technology, vol. 107, p. 83-89, Dol:10.1115/1.3225775.

[9] Ghozzi, Y., Labergere, C., Saanouni, K. Parrico, A. (2014). Modelling and numerical simulation of thick sheet double slitting process using continuum damage mechanics. International Journal of Damage Mechanics, vol. 23, no. 8, pp. 1150-1167, Dol:10.1177/1056789514520799.

[10] Lemaitre, J., and Desmorat, R. (2005). Engineering Damage Mechanics, Springer, Berlin, Heidelberg.

[11] Celentano, D.J., Chaboche, J.L. (2007). Experimental and numerical characterization of damage evolution in steels. International Journal of Plasticity, vol. 23, no. 10-11, p. 17391762, D0I:10.1016/j.ijplas.2007.03.008.

[12] Mashayekhi, M., Ziad-Rad, S., Parvizian, J., Niklewicz, J., Hadavinia, H. (2007). Ductile crack growth based on damage criterion: Experimental and numerical studies. Mechanics of Materials, vol. 39, no. 7, p. 623-636, D0l:10.1016/j. mechmat.2006.10.004.

[13] Hambli, R. (2001). Comparison between Lemaitre and Gurson damage models in crack growth simulation during blanking process. International Journal of Mechanical Sciences, vol. 43, no. 12, p. 2769-2790, D0l:10.1016/S0020-7403(01)00070-4.

[14] Teixeira, P., Santos, A.D., Pires, F.A., de Sa, J.M.A.C. (2006). Finite element prediction of ductile fracture in sheet metal forming processes. Journal of Materials Processing Technology, vol. 177, no. 1-3, p. 278-281, Dol:10.1016/j. jmatprotec.2006.04.059.

[15] Ganjiani, M. (2013). Identification of damage parameters and plastic properties of an anisotropic damage model by microhardness measurement. International Journal of Damage Mechanics, vol. 22, no. 8, p. 1089-1108, DOl:10.1177/1056789513482598.

[16] Desmorat, R., Otin, S. (2008). Cross-identification isotropic/ anisotropic damage and application to anisothermal structural failure. Engineering Fracture Mechanics, vol. 75, no. 11, p. 3446-3463, D0I:10.1016/j.engfracmech.2007.05.011.

[17] Malcher, L., Mamiya, E. (2014). An improved damage evolution law based on continuum damage mechanics and its dependence on both stress triaxiality and the third invariant. International Journal of Plasticity, vol. 56, p. 232-261, DOl:10.1016/j.jijplas.2014.01.002. 
[18] Mkaddem, A., Gassara, F., Hambli, R. (2006). A new procedure using the microhardness technique for sheet metal damage characterization. Journal of Materials Processing Technology, vol. 178, no. 1-3, p. 111-118, D0l:10.1016/j. jmatprotec.2006.02.018.

[19] Guduru, R.K., Darling, K.A., Kishore, R., Scattergood, R.O., Koch, C.C., Murty, K.L. (2005). Evaluation of mechanical properties using shear-punch testing. Materials Science and Engineering: A, vol. 395, no. 1-2, p. 307-314, D0l:10.1016/j. msea.2004.12.048.

[20] Sellamuthu, P., Collins, P.K., Hodgson, P.D., Stanford, N. (2013). Correlation of tensile test properties with those predicted by the shear punch test. Materials \& Design, vol. 47, p. 258-266, Dol:10.1016/j.matdes.2012.11.057.

[21] Abendroth, M., Kuna, M. (2006). Identification of ductile damage and fracture parameters from the small punch test using neural networks. Engineering Fracture Mechanics, vol. 73 , no. 6, p. 710-725, D0l:10.1016/j. engfracmech.2005.10.007.

[22] Mole, N., Cafuta, G., Štok, B. (2013). A method for optimal blank shape determination in sheet metal forming based on numerical simulations. Strojniški vestnik - Journal of Mechanical Engineering, vol. 59, no. 4, p. 237-250, DOI:10.5545/sv-jme.2012.989.

[23] Vrh, M., Halilovič, M., Štok, B. (2008). Impact of Young's modulus degradation on springback calculation in steel sheet drawing. Strojniški vestnik - Journal of Mechanical Engineering, vol. 54, no. 4, p. 288-296.
[24] Gantar, G., Sterzing, A. (2008). Robust design of forming processes, Strojniški vestnik - Journal of Mechanical Engineering, vol. 54, no. 4, p. 249-257.

[25] Vegelj, D., Zajec, B., Gregorčič, P., Možina, J. (2014). Adaptive pulsed-laser welding of electrical laminations. Strojniški vestnik - Journal of Mechanical Engineering, vol. 60, no. 2, p. 106-114, D0I:10.5545/sv-jme.2013.1407.

[26] Slavič, J., Bolka, Š., Bratuš, V., Boltežar, M. (2014). A novel laboratory blanking apparatus for the experimental identification of blanking parameters. Journal of Materials Processing Technology, vol. 214, no. 2, p. 507-513, D0I:10.1016/J.jmatprotec.2013.10.006.

[27] Kachanov, L. (1958). On creep rupture time. Proc Acad Sci USSR DIv Engńn Sci, p. 26-31,

[28] Lemaitre, J. (1992). A Course on Damage Mechanics. Springer, Berlin, Heidelberg, D0l:10.1007/978-3-662-02761-5.

[29] de Souza Neto, E.A., Perić, D., Owen, D.R.J. (2001). Computational Methods for Plasticity: Theory and Applications. John Wiley \& Sons, Chichester, Dol:10.1002/9780470694626.

[30] Voce, E. (1948). A Practical Strain-Hardening Function. Acta Metallurgia, vol. 51, p. 219-226.

[31] Klingenberg, W., Singh, U.P. (2005). Comparison of two analytical models of blanking and proposal of a new model. International Journal of Machine Tools and Manufacture, vol. 45, no. 4-5, p. 519-527, Dol:10.1016/j. ijmachtools.2004.09.002. 